\begin{tabular}{|c|c|c|}
\hline$A R$ & $\begin{array}{l}\text { European Association for the } \\
\text { Development of Renewable Energies, Environment } \\
\text { and Power Quality (EA4EPQ) }\end{array}$ & $\begin{array}{l}\text { International Conference on Renewable Energies and Power Quality } \\
\text { (ICREPQ'12) } \\
\text { Santiago de Compostela (Spain), 28th to 30th March, } 2012\end{array}$ \\
\hline
\end{tabular}

\title{
Energy Reductions in the Pulp-and-Paper Industry by Upgrading Conventional Pumping Systems through the Installation of VFDs - A Case Study
}

\author{
António Bonifácio ${ }^{(1,2)}$, Pedro Coelho ${ }^{(2)}$, Inácio Fonseca ${ }^{(1)}$ and Fernando Lopes ${ }^{(1,3)}$ \\ ${ }^{(1)}$ Department of Electrical Engineering - Instituto Superior de Engenharia de Coimbra \\ Rua Pedro Nunes, Quinta da Nora - P-3030-199 Coimbra (Portugal) \\ Phone: +351 239790320, e-mail: \{inacio,flopes\}@isec.pt \\ ${ }^{(2)}$ Soporcel, SA, Maintenance Management Direction, \\ Lavos, Apartado 5 - 3081-851 Figueira da Foz \\ Phone: +351 233940411, e-mail: \{antonio.bonifacio,pedro.coelho\}@portucelsoporcel.com \\ (3) Telecommunications Institute - Pólo de Coimbra, \\ Pólo II da Universidade de Coimbra, Pinhal de Marrocos, 3030- Coimbra, Portugal \\ Phone: +351 239796236, e-mail: fernando.lopes@co.it.pt
}

\begin{abstract}
In this paper we intend to demonstrate the benefits that can be obtained by upgrading conventional pumping systems, i.e, without speed control, pervasive in the older project Pulp-and-Paper industries, through the installation of Variable Frequency Drives (VFDs). The main objective is to significantly reduce the energy consumption and associated cost, while simultaneously avoiding the production of excess Greenhouse Gases (GHGs), contributing to the global sustainability efforts.
\end{abstract}

A case study is presented, where a conventional level control system, based on an automatic valve and a constant speed driven pump, is converted to a control strategy based on the combined actuation on the valve and on the speed of the pump. For this study, it is shown that a yearly energy reduction of about $60 \%$ is achieved. This reduction, associated with a $160 \mathrm{~kW}$ motor, results in a yearly energy reduction of about $533 \mathrm{MWh}$ and an associated reduction of about 250 tonnes $\mathrm{CO}_{2}$. Negative effects in the power quality such as harmonics and common-mode currents must be considered, but could be kept under acceptable limits.

With the results presented in this work, fully developed in an actual industrial environment, we aim to motivate those in the industry to pursue similar objectives.

Key words: Energy Efficiency, Power Quality, Pump, Pulp-and-Paper Industry, VFD, GHG, Sustainability.

\section{Introduction}

In the Pulp-and-Paper industry, about $30 \%$ of the total consumed electrical energy is associated with pumping systems [1]. As a result, any optimization in theses systems can potentially result in very significant reductions in the overall energy costs. It can also contribute to the public image of the industry, by reducing the GHGs and thus demonstrating the Goodwill towards sustainability. However, a detailed case analysis and simulation must be always performed to guarantee reasonable investment return conditions.
The production process associated with a Paper Machine (PM) involves the displacement of large quantities of paper pulp with consistencies in the order of $4 \%$. Many initial projects, for older and not so old paper plants, do not include speed control for the pumping systems. This is due to several factors, including the uncertainty about future regimes, the extra costs associated with the VFDs, and optimizations implemented during the project itself and the erection and the commissioning of the plant. The experience of field engineers in these plants allows to readily inferring that, a control system where the output variable is determined by an automatic valve that exhibits an average value of only $30 \%$, has a great potential for optimization. However, to validate the change, a detailed analysis and simulation is recommended.

In terms of the analysis, the starting point is the calculation of the value for the hydraulic power required for the given pulp flow. This calculus must be complemented with the characteristics of the existing centrifugal pump, the power of the electrical induction motor and the overall group efficiency [2,3,4,5]. A second aspect of the analysis is the characteristics of the electrical installation, namely the quality of the energy in the supply bus, focusing on the Total Harmonic Distortion (THD). This parameter should be analyzed before and after the installation of the VFD. Another aspect is the consideration of the expected negative effects arising from parasitic conduction and radiation signals generated in the cables supplying the VFD and the motor. Associated with these, many aspects such as the electrical motor characteristics concerning the Isolation Class, the need for an isolated bearing, the type of receiving gland for the motor cable, the quality of the Service and Protection Earth, the type of cable and the quality of its metallic shield as well as the three-phase symmetry of the cable, all should be considered. 
Furthermore, it is of fundamental interest to analyze the main process variables such as pressure, viscosity, temperatures and flow in all working regimes. Concerning the validation of the pump behaviour at different speeds, manufacturer simulation software can be used $[4,6]$.

In this work a real pulp-and-paper industry case is presented, where a conventional level control system, for a paper pulp break tank, which is based on an automatic valve and a constant speed driven pump, is converted to a control strategy based on the actuation on a variable speed motor-pump through the insertion of a VFD.

The paper will be organized as follows. In Section 2 the case study is presented, including the calculation of the theoretic value for the hydraulic power and the validation of the obtained results by software simulation using a pump manufacturer application. In Section 3, the installation procedure is detailed, presenting the used VFD, the cable characteristics and the overall installation geometry. A short discussion on THD, common mode currents and on the use of filters to minimize Pulse Width Modulation (PWM) side effects is also presented. Section 4 deals with the commissioning aspects of the modified installation, describing initial tests, VFD parameterization and the tuning of the new control system. In Section 5, results comparing process variables and THD components before and after speed control are presented. This section includes an energy reduction analysis and an economic savings analysis. Finally, Section 6 finishes the paper with the main conclusions. This Submission Digest intends to represent a preliminary version of the final paper.

\section{Case Study}

The case study refers to a pumping system for the dry-break tank, associated with a paper machine silo. The whole dry-broke recovery system is illustrated in Fig. 1.

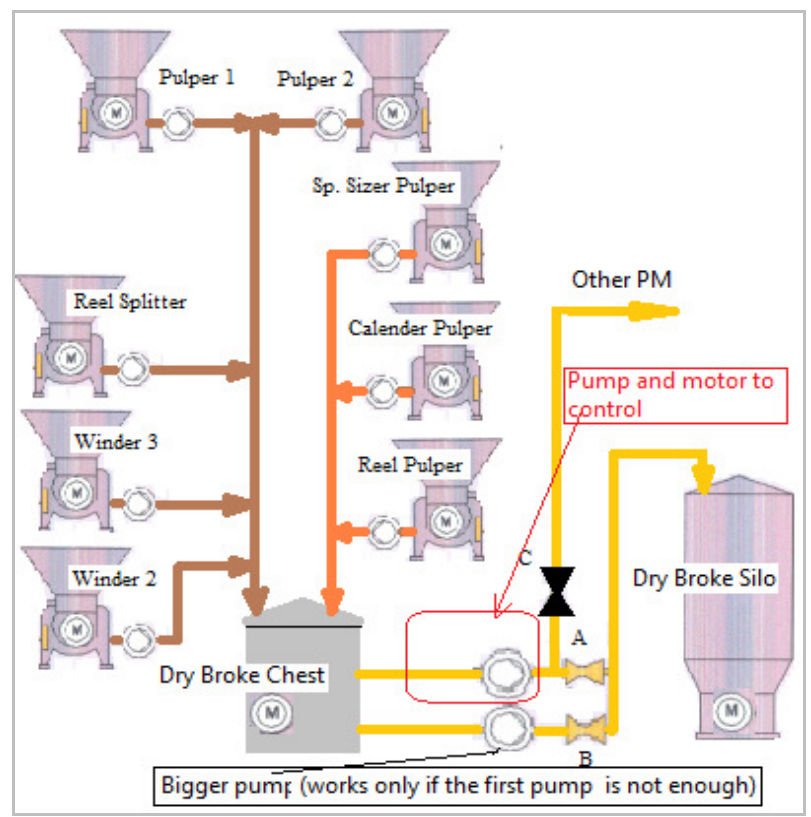

Fig. 1 - Dry broke recovery system

The pump works with relatively constant speed with valve 'A' controlling the flow as a function of the required level.
Local process analysis showed an average opening of the valve between $13 \%$ and $20 \%$ in normal conditions, that is, without break in the PM. When needed, pump ' 2 ' is activated to avoid level overflow. Pump ' 2 ' activity is, on average, under $10 \%$ of the overall process time. Under these circumstances, referring to the average opening of the valve, it can be expected that significant energy gains can be obtained while delivering the same useful work.

First we start by calculating the theoretic required hydraulic power and the associated power in the centrifugal pump rotating axis [6]:

$$
P_{h}=\frac{q \times h \times g \times p}{3.6 \times 10^{6}} \quad \text { (1) } \quad P_{v}=\frac{P_{h}}{\eta}
$$

where: $\begin{array}{lll}\mathrm{P}_{\mathrm{h}} & \rightarrow & \text { hydraulic power, }(\mathrm{kW}) \\ \mathrm{P}_{\mathrm{v}} & \rightarrow & \text { power on shaft, }(\mathrm{kW}) \\ \mathrm{q} & \rightarrow & \text { flow, }\left(\mathrm{m}^{3} / \mathrm{h}\right):(700-\text { from project }) \\ \rho & \rightarrow & \text { liquid density, }\left(\mathrm{kg} / \mathrm{m}^{3}\right): 1000 \\ \mathrm{~g} & \rightarrow & \text { gravity, }\left(\mathrm{m} / \mathrm{s}^{2}\right): 9.8 \\ \mathrm{~h} & \rightarrow & \text { head, }(\mathrm{m}):(65-\text { from project }) \\ \eta & \rightarrow & \text { pump efficiency: } 0.73\end{array}$

From Eq. (1) and Eq. (2), with the ABS BA 300/250-60 pump [4,5] and for the proposed process variables and the pump project flow and head, the hydraulic power is:

$$
P_{h}=123.99 \mathrm{~kW} \quad P_{v}=116.75 \mathrm{~kW}
$$

For a pump efficiency of $73 \%$ the axis power is:

$$
P_{h}=85.23 \mathrm{~kW} \quad P_{v}=169.85 \mathrm{~kW}
$$

Since the electrical motor has a nominal axis power of $160 \mathrm{~kW}$, it can be concluded that it is under-dimensioned. As a result, for the total head of $65 \mathrm{~m}$ and an approximately constant speed, the valve must strongly restrict the flow in order to keep the required axis power under the motor capability and not overload it. On the other hand, if a VFD is used to drive the motor and an unrestricted flow is permitted by a $100 \%$ open valve, the actual height of $26 \mathrm{~m}$ and a measured $15 \mathrm{~m}$ pressure loss in the line, an effective water column of only $41 \mathrm{~m}$ is obtained for the pump compression effort. That is, the new hydraulic power and axis power are, respectively:

$$
P_{h}=85.23 \mathrm{~kW} \quad P_{v}=116.75 \mathrm{~kW}
$$

This simple analysis permits to conclude that, by lowering the pressure a $53 \mathrm{~kW}$ power reduction can be achieved, allowing for the motor to span the whole power working range and still have some additional margin to increase speed. However, there are still speed limits that must be imposed, what can be easily achieved by activating protections in the VFD. In contrast, in the direct conventional connections, only short-circuit and overloading protections are usually installed.

In order to validate the previous results, a simulation for the pump power at various speeds was performed, using pump manufacturer software [4]. Results are shown in Fig. 2. This power reduction potential is mainly a consequence of the Affinity Laws applied in this context, with flow proportional to the speed but power proportional to the cube of the speed $[2,3]$. 


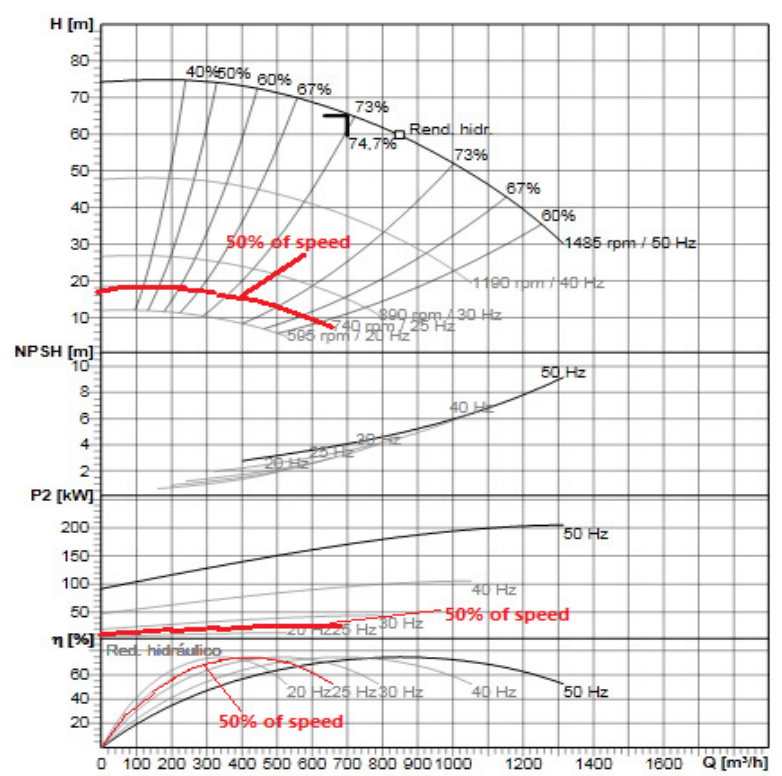

Fig. 2 - Pump performance - Pump type: ABS BA 300/250-60.

\section{Field Implementation}

The field installation of the VFD and the associated cable selection and layout require special attention. It is mandatory to follow manufacturer instructions and recommendations. These include procedures that aim to minimize noise conduction and radiation from the cables to the equipments and systems that they connect directly or that are in their neighbourhood.
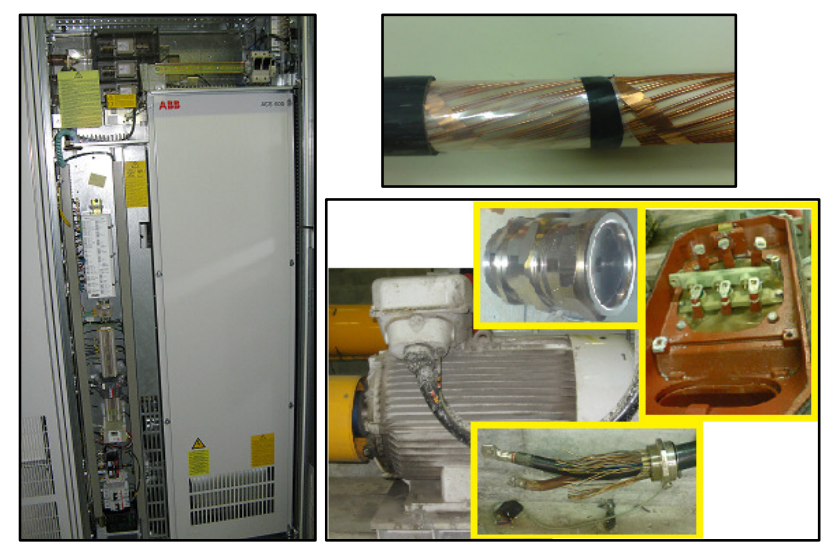

Fig. 3 - VFD, cable, special gland, connection box, induction motor and terminals.

The quality of the Earth circuit and the cable shield, as well as the quality of their connections, are fundamental to minimize parasitic currents that tend to interfere with communication signals such as those in the Fieldbus. Fig. 3 illustrates the actual components and environment. When selecting the Drive ${ }^{1}$, the requirement to fulfil EMC and EN directives can be specified [7]. In this work, $d v / d t$ filters, available in the VFD, were used.

The circuit capacitance and inductance effects are very significant in applications using VFDs, mainly due to the PWM technology used in the drives. In this work the PWM signal has a programmable basis frequency around $3 \mathrm{kHz}$ [7]. This technology includes circuits with fast switching times in the order of 100 to $300 \mathrm{~ns}$.

\footnotetext{
${ }^{1}$ Same as VFD
}

As an example, for a $950 \mathrm{~V} \mathrm{DC}$ Bus in the drive, and for a $200 \mathrm{~ns}$ switching time, without $d v / d t$ filters, the transient voltage excursion rate would be:

$$
\frac{d v}{d t}=\frac{950}{200 \times 10^{-9}}=4.75 \times 10^{9} \mathrm{~V} / \mathrm{s}
$$

The use of $d v / d t$ filters before the cable connections to the motor can reduce this effect by smoothing large voltage rates and thus limiting large current variations.

The cable length must also be taken into account since the cable capacitance is proportional to its length. In addition to the power cable, distributed capacitances exist in the whole installation. A model for these capacitances is presented in Fig. 5.

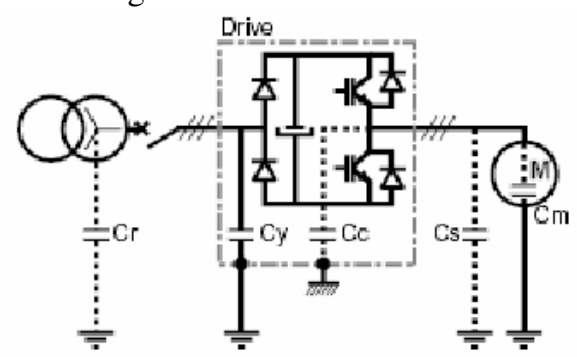

Fig. 5 - Installation parasitic capacitances model [8].

Associated with the stray and parasitic capacitances and the fast voltage transitions are common-mode currents than mostly flow through the earth circuits, shields and armatures, creating noisy voltage differences along the earth circuits. An example of a common-mode current waveform is shown in Fig. 4.

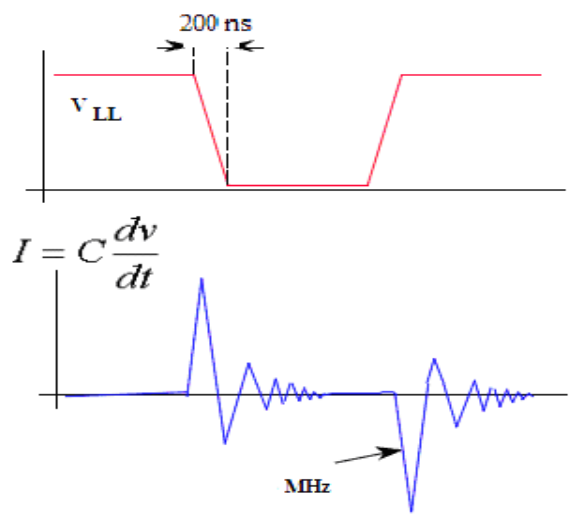

Fig. 4 - Common-mode current from $d v / d t$ and capacity adapted from [8].

The common-mode currents depend on the cable length and circuit capacitance as well as on the characteristics of the switching transients. The created ground voltage can be estimated by:

$$
V_{\text {Ground }}=L_{\text {ground }} \times \frac{d i}{d t}+R_{\text {Ground }} \times i
$$

A $d v / d t$ filter can limit high amplitude common mode currents and thus reduce unwanted ground voltages. This effect can also be minimized using power cables with good quality shields. This installation used the Drive manufacturer recommended copper shielded cable to power the Drive $(15 \mathrm{~m})$ and between Drive and motor (65m). This allows the common-mode currents to have a preferred low impedance ground returning path, minimizing voltage differences within the earth circuits. 
Better shielding characteristics cable can be selected for the motor run. In addition, because common-mode currents can flow through bearings and degrade them, the motor has an insulated bearing on the non-driving side [9].

A related problem is the transmission line behaviour of the output cable with the high frequencies generated by the VFD. For an unmatched line, there will be reflected waves. This phenomenon creates over-voltages at the motor terminals that can result in micro-ruptures in the winding isolation, especially in the first turns of the coils. It will also contribute to the corona effect within the motor. These negative effects can induce failures in the motor and shorten its lifetime [8,9]. To estimate motor peak over-voltage, including its dependence on the use of $d v / d t$ filters and on cable length, the manufacturer produced a set of curves [7]. Using the $d v / d t$ filters and a cable length of $70 \mathrm{~m}$, the peak voltage can reach 2 times the nominal Drive output. For lengths over $70 \mathrm{~m}$ the manufacturer recommends consultation and, for example, an additional RLC filter may be considered [7]. In this application a safe operation was assured by using $d v / d t$ filters with a $65 \mathrm{~m}$ cable length and a Class-F reinforced isolation motor.

\section{Commissioning and Tuning}

After installation, and before main power start-up, it is highly recommended that control measurements, including megaohm continuity, are performed in cables, Drive and motor, to avoid any accident and minimize commissioning delays $[7,10]$. Drive parameter setting is then performed with a powered drive but without powering of the motor. Very important parameters are current and torque limits estimated for the practical situation. The upper speed limit does not need to be programmed since, as can be confirmed analyzing Fig. 2, it will be automatically limited by the combined current and torque limits, given that the Drive implements the DTC $^{2}$ technique and the power has a cubic dependence on the angular velocity. On the other hand, the lower speed limit is important since its value must guarantee the hydrostatic pressure corresponding to the silo physical height and the non inversion of the flow, considering that paper pulp lines are usually not provided with retention-type valves. A further restriction must be programmed in order to guarantee an interlock that will stop both pump motors when the level in the tank drops below $25 \%$. This strategy aims to avoid air from entering the circuit, decreasing efficiency and creating noise and line vibration. Finally, valve ' $A$ ' must be permitted to be driven open only when the motor is already rotating and for values grater than $2 \%$ for the actuated variable.

Concerning the control strategy and tuning, changes are needed since the motor speed is correlated with valve ' $A$ ' in split-range mode. In addition, valve ' $\mathrm{B}$ ' must be made dependent on the extra pump being activated and the circuit switching implemented by valve ' $C$ '. In the test and commissioning phase, tuning the control loop is an important aspect in order to keep upstream and downstream process stability. This is required since, in complex processes such as the PM process, there is interdependency between neighbouring sub-processes.

\footnotetext{
${ }^{2}$ Direct Torque Control
}

The most common method used in industry practice, for the tuning of PID controllers, is the Try-and-Error method based on the second heuristic Ziegler-Nichols method [11]. Results for the tuning are shown in Fig. 6.

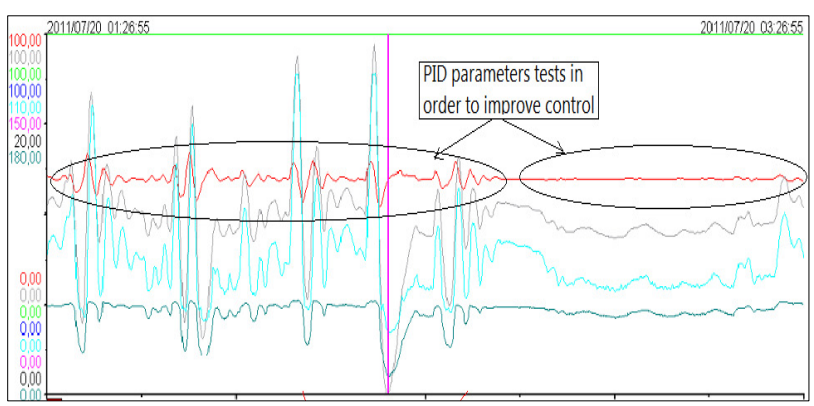

Fig. 6 - Results for the tuning of the level control.

\section{Installation Results}

The register of process variables and field signals before and after VFD installation is of fundamental interest to compare advantages and limitations of the change. An illustration of field measurements is presented in Fig. 7.
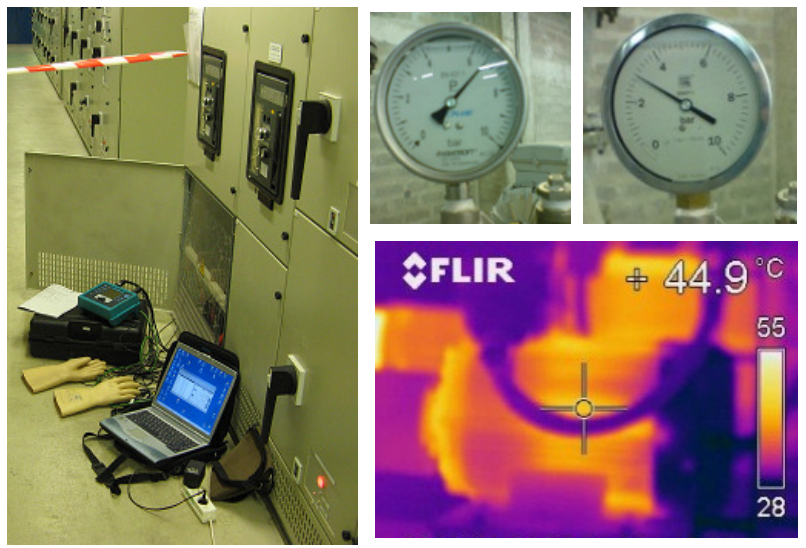

Fig.7- Samples: a) - Energy analyzer; b) - Pressure measurement; c) - IR temperature motor measurement.

One immediate observation was the confirmation of a line pressure reduction by $4 \mathrm{Bar}(400 \mathrm{kPa})$ for similar process conditions. This reduction has effects both on the power reduction and on the generated noise. A second observation is the reduction on the motor temperature by $12{ }^{\circ} \mathrm{C}$ at low speeds and by $18{ }^{\circ} \mathrm{C}$ at the speed limit. The VFD reduces the quality of the power waveform applied to the motor resulting in a temperature increase associated with the phenomena discussed in Section 4. However, the large power reduction has a stronger effect and thus the overall motor temperature decreases. A further observation was the strong reduction in pulp leakages due to the occasional valve malfunctioning, with a significant decrease on the need to periodically cleaning to guarantee an acceptable level of housekeeping.

In the new control strategy, the valve opens in a Drive controlled ramp profile, replacing the previous 2 seconds fast opening. This resulted in high differential pressure, increasing the internal friction between the non fixed components. Furthermore, the valve is now mostly full open, reducing the control induced wear. Wear due to cavitations is also strongly reduced since this phenomenon happens mostly for low opening conditions. 
Harmonics Analysis: A well known disadvantage of using VFDs is the unavoidable reduction of the energy quality in the power bus, mainly through the increase in the THD [12,13]. The power bus is supported by an EFACEC $15 \mathrm{kV} / 690 \mathrm{~V}-3.15 \mathrm{MVA}$ transformer, where a $400 \mathrm{kVA}$ VFD at $80 \%$ load was already installed. For convenience, a deactivated $400 \mathrm{kVA}$ ABB ACS607 Drive was used at about $15 \% \operatorname{load}^{3}$ for the test pump. Fig. 8 shows the quality measures in the bus before the new VFD.

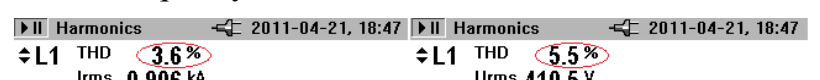

Irms $0.906 \mathrm{kA}$

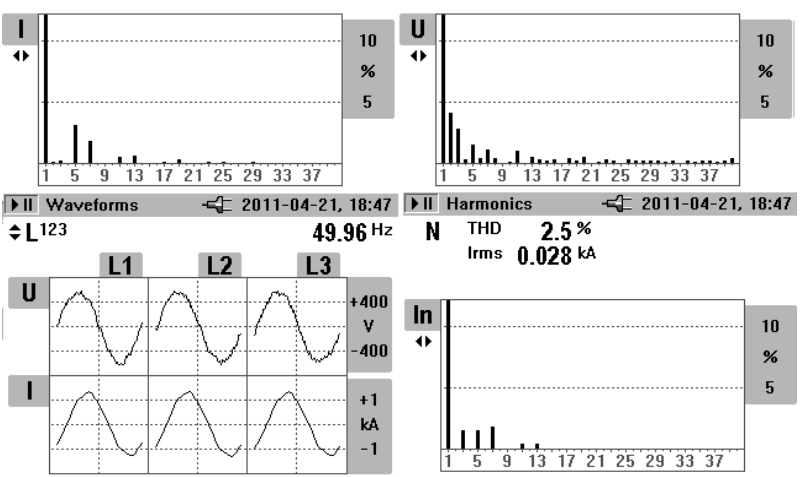

Fig. 8- Harmonics before installation of the VFD.

On the other hand, in Fig. 9, we present the same power bus signals after VFD installation, in the most frequent process situation. An increase in the voltage THD can be clearly observed from a 5.5\% THD to a $6.9 \%$ THD.

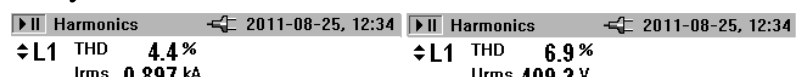

$$
\text { Irms } 0.897 \mathrm{kA} \quad \text { Urms } 409.3 \mathrm{~V}
$$

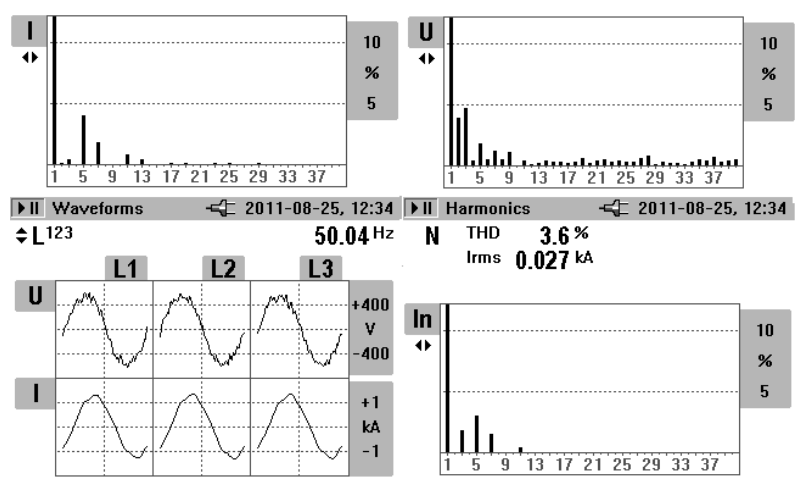

Fig. 9 - Harmonics after installation of the VFD.

The THD induced by these two conventional VFDs in this specific bus, under these specific loads, is under the $8 \%$ recommendation from EN 50160:2010 [14]. However, in exceptional conditions, when most direct powered motors on the same bus are turned off, and thus when the relative VFD driven power increases, a THD value as high as $10 \%$ can be present. This means that harmonics filters must be used if problems such as transformer excessive heating are observed [15]. There was no observable transformer temperature increase, as it was measured between $45^{\circ} \mathrm{C}$ and $49^{\circ} \mathrm{C}$, for an external July temperature between $24^{\circ} \mathrm{C}$ and $29^{\circ} \mathrm{C}$, both before and after VFD installation. It also means that further increasing the number of VFDs in this bus requires detailed harmonics filtering considerations. On the other hand, if a better power matched VFD is used, slightly lower energy consumption would result.

\footnotetext{
${ }^{3}$ Lower efficiency working condition for the VFD-motor
}

Power and Energy Analysis: One week power and energy was registered resulting in the graphs in Fig. 10. Using the data in Fig. 10 and extrapolating for one year, we get an average power reduction of $60 \mathrm{~kW}$ and an average annual energy reduction of about $533 \mathrm{MWh}$, which represents a yearly energy reduction of about $63 \%$.

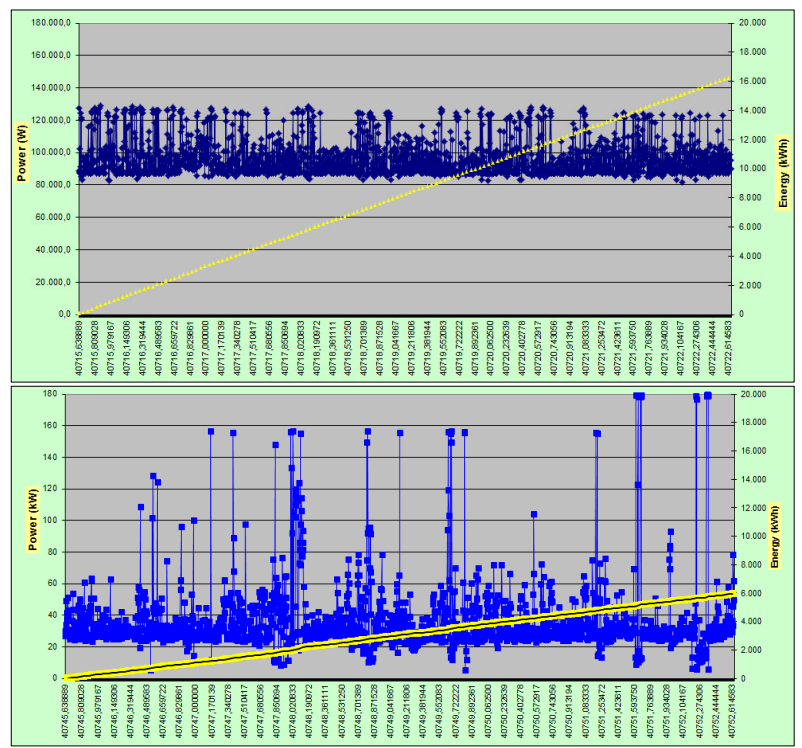

Fig. 10 - Power and Energy: before (top) and after (bottom) VFD installation - week $21 / 6 / 2011$ to $28 / 6 / 2011$.

These energy savings represent a significant contribution for sustainability efforts (Kyoto, Copenhagen, Cancun) with the reduction of about 250 tonnes of $\mathrm{CO}_{2}$ per year'. This confirms the success of the installation given that these were the main objectives of the upgrading work.

\section{Economic Analysis}

Method 1: To estimate the success from the economic point of view [5,16,17], Eq. (8) can be used for a simplified analysis with a fixed operating regime (i):

$$
S=\sum_{i}\left(\frac{P_{I M}^{i}}{x_{I M}^{i}}-\frac{P_{I M-V F D}^{i}}{\eta_{I M-V F D}^{i}}\right) \times h^{i} \times C^{i}
$$

Considering 51 weeks annual activity and a price of $50 € / \mathrm{MWh}\left(p u^{5}\right)$ results in an annual savings $\mathrm{S}=27.785 €$, where:

$\begin{array}{lllr}\mathrm{S} & \rightarrow & \text { Annual savings: } & \text { (€/year) } \\ \eta_{\mathrm{IM}} & \rightarrow & \text { IM }^{6} \text { Efficiency (decimal): } & 90 \% \\ \eta_{\mathrm{IM}-\mathrm{VFD}} & \rightarrow & \text { Efficiency of system (IM, VFD): } & 86 \% \\ \mathrm{P}_{\mathrm{IM}} & \rightarrow & \text { Mechanical power (only IM): } & 95 \mathrm{~kW} \\ \mathrm{P}_{\mathrm{IM}-\mathrm{VFD}} & \rightarrow & \text { Mechanical power (with VFD): } & 35 \mathrm{~kW} \\ \mathrm{~h} & \rightarrow & \text { Occupation, (hours/year): } & 8.568 \mathrm{~h} \\ \mathrm{C} & \rightarrow & \text { Price reference }(p u): & 0,05 € / \mathrm{kWh} \\ \mathrm{i} & \rightarrow & \text { Operating regime: } & \text { all time }\end{array}$

Method 2: To calculate the energy cost from the field measurements presented in Section 5, where the annual estimated savings was $532.950 \mathrm{kWh}$. To simplify, the value of $0.05 € / \mathrm{kWh}$, exempt from taxes and other charges, is considered for $p u$. The estimated savings are:

$$
S_{(\text {energy saving })}=26.647 € / \text { year }
$$

\footnotetext{
${ }^{4}$ Considering $0,47 \mathrm{~kg} \mathrm{CO} / \mathrm{kWh}$ [18]

${ }^{5} \mathrm{pu}$ - per-unit equivalent (rounded to $50 € / \mathrm{MWh}$ )

${ }^{6} \mathrm{IM}$ - Induction Motor
} 
It is concluded that in both methods we arrived at similar and very significant values. Thus, it is adequate to use Eq. (9) and its simplification for an estimate of the forecast Return On Investment (ROI). Considering the costs of conversion estimated at approximately $€ 17.000$, we get a relationship between savings and costs of 1,567, which results in an economically interesting ROI, with a short payback time of only 232 days or less than one year. However, these results must be adjusted in the cases where specific consultation, extra harmonics filters, better cables or new improved characteristics motors are required. As a curiosity, the average annual energy consumed by a typical Portuguese family is $2.640 \mathrm{kWh}$ [17]. The annual $532.950 \mathrm{kWh}$ savings is enough for the annual energy requirements of 201 families. It is indeed a very rewarding result, to confirm how a relatively small engineering project can contribute for sustainability.

\section{Conclusions}

From this study, on the upgrade of conventional pumping systems in the Pulp-and-Paper industry to include variable speed control, the following conclusions can be drawn:

- Technically, it is a relatively simple project and within the skills of most industrial organizations;

- The technology is affordable, however, installation is dependent on procedural production planning;

- An initial analysis of the necessary hydraulic power is mandatory. Gains are dependent on initial project.

Some disadvantages are associated to the variable speed control of the induction motor:

- Increase in parasitic currents in cables and ground circuits, that may affect communication systems and develop voltage spikes in the motor windings;

- Depending on load, may increase temperature on cables and motor - not tested for the cables here;

- Possible increased costs with additional filtering on the Drive, as well as costs with motors and cables with improved characteristics for VFD applications;

- Worsening of the THD on the power buses - studying alternatives $[13,15]$;

- The installation of VFDs increases the likelihood of raising the system downtime and requires well-trained maintenance teams.

However, very important advantages outweigh the listed disadvantages and are reviewed here:

- The pump power was significantly reduced with the speed of the pump - power is proportional to the cube of the angular velocity;

- The consumed energy was strongly reduced with very significant economic gains;

- There are big savings in GHGs, improving the public image of the Company and promoting its Goodwill;

- The optimization of the control favoured the temporal stability of the controlled variables and decreased the temperature of the engine;

- The motor is now starting and stopping in a smooth ramp profile, avoiding vibration caused by cavitations and water hammer;

- Reduced leakage from the seal of the valve with unnecessary maintenance and cleaning costs;
- The line pressure decreases, reducing friction and wear in the valve and also the effects of cavitations.

In conclusion, it can be stated that in Pulp-and-Paper industries, with intensive energy consumption associated to pumping systems, there exists an enormous potential for improving the energy efficiency and achieve large energy reductions. These reductions can represent huge investment returns while decreasing the emission of GHGs and thus contributing to global sustainability and to meet related International Protocols. This direction of action further improves the public image of the industry and the respect from customers, suppliers and the general public. This case study also intends to motivate those in the same industry area to pursue the same objectives.

\section{Acknowledgement}

Special thanks to Soporcel SA for permitting all the plant tests and to all the persons involved in the field work.

\section{References}

[1] US Department of Energy - OIT, "Motor System Usage in Forest Products", Industry of the Future-Forest Products, January 1999, Available from:

www.energystar.gov/ia/business/industry/pulpmtr.pdf.

[2] Hydraulic Institute, Europump and USA Department of Energy, "Variable Speed Pumping-A Guide to Successful Applications - Executive Summary", May 2004.

[3] Michael Offik, P.E., Frank Stauble and Roger Turley, "Pump energy savings with VFDs", Pump up Energy Savings, PlantServices, June 2005.

[4] ABS - Scanpump - Sulzer, Pump Supplier.

[5] A. Almeida, F. Ferreira and D. Both, "Technical and Economical Considerations in the Application of Variable Speed Drives with Electric Motor Systems", IEEE Trans. on Industry Applications, Vol. 41, Jan/Feb 2005.

[6] Engineering Tool Box. Available from: www.engineeringtoolbox.com/pumps-power-d_505.html.

[7] ABB, "ABB Drives - Startup, Firmware \& Hardware Documentation", 2000. With the SIP800 Project.

[8] Gleston F. de Castro "Inversor de Frequência - Conceitos e Técnicas de Aplicação", TecnAuto. Available from: www.tecnaut.com.br/old/utilidades/Tecnicascuidados.pdf.

[9] Alpa Shah, "Paradigm shift in proper selection criteria of VFD cable for variable frequency drives", Cement Industry Technical Conf., 2011 IEEE-IAS/PCA 53rd.

[10] Soporcel, SA, Internal Safety Rules.

[11] Katsuhiko Ogata, "Modern Control Engineering", 4th Edition: Prentice Hall 2002.

[12] Wilsun $\mathrm{Xu}$,"Status and future directions of power systems harmonics analysis", IEEE Power Engineering Society General Meeting, Vol.1, pp. 756-761, 6-10 June 2004.

[13] MA. Castro, J. Carpio, A. Colmenar and J.L. Hernandez, "Harmonics in Power Systems", in ICREPQ 2009. Valencia, Spain, April 2009.

[14] CENELEC, EN 50160:2010." Voltage Characteristics in Public Distribution Systems", January 2011.

[15] Frederick Hoadley, "Comparison of methods for the mitigation of line disturbances due to PWM AC Drives", Pulp and Paper Industry Technical Conf. 2007, pp. 78-92.

[16] F. Ferreira, P. Fonseca, F. Oliveira and A. Almeida, "Considerações Técnico-Económicas sobre Variadores Electrónicos de Velocidade", Energia, N. ${ }^{\circ}$ 1, pp. 11-15, Janeiro/Abril 2006. In Portuguese.

[17] A. Almeida et al., "VSDs for Electric Motor Systems". European Commission - DGTREN, SAVE II Program, ISR - University of Coimbra, 2000-2001.

[18] D.R., $2^{\mathrm{a}}$ Série - Despacho nº17313/2008-Portuguese Law. 